\title{
AVALIAÇÃO DAS PROPRIEDADES FÍSICAS, gUÍMICAS E SENSORIAL DE PREFERÊNCIA DE GOIABAS EM CALDA INDUSTRIALIZADAS ${ }^{1}$
}

\author{
A. C. K. SATO ${ }^{2}$, E. J. SANJINEZ-ARGANDOÑA ${ }^{2}$, R. L. CUNHA ${ }^{2, *}$
}

\begin{abstract}
RESUMO
Quatro marcas de goiabas em calda foram submetidas a análises físico-químicas, de cor e textura instrumentais e teste sensorial de preferência, a fim de avaliar as diferenças entre os produtos comerciais. As mesmas análises foram efetuadas em uma goiaba in natura madura, a fim de avaliar os possíveis efeitos do processamento na qualidade do produto. De maneira geral, observou-se grandes diferenças entre os produtos das diferentes marcas, e muitas vezes entre os frutos de um mesmo fabricante. As análises químicas mostraram que o teor de açúcares da maior parte dos produtos está entre 22 e 30\%, com exceção de uma amostra que mostrou um valor bem mais elevado (ao redor de 40\%). A análise sensorial mostrou que esta amostra com maior teor de açúcares foi a mais preferida em relação à doçura. $\mathrm{Na}$ análise de cor foram observados menores valores de $\mathrm{a}^{*}$ em relação à fruta in natura, possivelmente devido à degradação dos carotenóides da goiaba. A luminosidade das goiabas em calda também é maior que da fruta in natura, devido à presença dos açúcares. Esta entrada de açúcares na fruta junto com o processamento térmico utilizado pode ter causado possivel gelificação da pectina, aumentando a dureza, firmeza e elasticidade de algumas amostras processadas, quando comparadas à fruta fresca. No entanto, em alguns casos foi visível o efeito de processamentos mais drásticos, que levaram à perda da estrutura celular, observada pelos baixos valores das propriedades mecânicas. Em relação à textura e aparência, a amostra mais dura foi a preferida.

Palavras-chave: goiaba; propriedades mecânicas; cor.
\end{abstract}

\section{SUMMARY}

PHYSICAL, CHEMICAL AND SENSORIAL ANALYSES OF INDUSTRIALIZED GUAVA IN SYRUP. Four brands of canned guava were submitted to physico-chemical, sensory (preference test) and instrumental color and texture analyses, in order to evaluate the differences between commercial products. The same analyses were made on a fresh, mature guava, to evaluate possible effects of processing on the quality of the final product. There were considerable differences between the distinct brands, and occasionally differences could be found between samples from the same manufacturer. The chemical analyses showed that most of the samples contained between 22 and $30 \%$ of sugar, except for one sample, which had a higher content, around $40 \%$. The preference test showed that the consumers preferred the sweetness of the sample with the highest sugar content. Lower values for the chroma parameter $\mathrm{a}^{*}$ were found in the commercial samples than in the fresh fruit, probably due to carotenoid degradation. The canned guava samples were lighter (higher values for $\mathrm{L}^{*}$ ) than the fresh fruit, due to the presence of sugar. The penetration of sugar into the fruit during heat processing may have caused pectin gelation, increasing the hardness, firmness and elasticity of some of the processed samples as compared to the fresh fruit. However in some samples, drastic process conditions were readily apparent, leading to loss of cellular structure, which could be observed from the low values obtained for the mechanical properties. With respect to texture, the hardest sample was preferred. Keywords: guava; mechanical properties; color.

\section{1 - INTRODUÇÃO}

O cultivo da goiaba é um dos mais importantes em países tropicais e subtropicais. O Brasil é um dos maiores produtores mundiais da fruta, junto com outros países como o México, o Paquistão e a Índia. O Estado de São Paulo é o maior produtor de goiaba no país, com 6 mil hectares plantados, o que totaliza cerca de $70 \%$ da produção nacional [5]. A alta perecibilidade, juntamente com a falta de disponibilidade de armazenamento durante os meses de pico de processamento industrial/safra, contribuem para perdas pós-colheita ao redor de $30 \%$ [10].

O processamento de frutas em calda é uma alternativa promissora para a sua conservação por proporcionar um sabor agradável, com o aumento da doçura, e

\footnotetext{
Recebido para publicação em 12/12/2002. Aceito para publicação em 27/10/2004 (001031).

2. Departamento de Engenharia de Alimentos - Faculdade de Engenharia de Alimentos - Universidade Estadual de Campinas. Caixa Postal 6121. CEP: 13083-970. Campinas-SP, Brasil. E-mail: rosiane@fea. unicamp.br

* A quem a correspondência deve ser enviada.
}

permitir uma boa conservação do produto por tempos longos. Porém, as características físicas e sensoriais das frutas em calda industrializadas mostram grandes diferenças entre as marcas encontradas no mercado, e inclusive entre produtos de uma mesma marca.

A qualidade e aceitabilidade de produtos alimentícios encontram-se intimamente associadas aos parâmetros sensoriais de cor e textura. A preservação destes parâmetros influencia na qualidade final do produto, e suas transformações dependem do tipo de tratamento ao qual as frutas são submetidas. A coloração rosada da goiaba se deve, principalmente, aos carotenóides presentes, sendo que o licopeno representa cerca de $80 \%$ dos carotenóides da fruta [11]. O licopeno inibe o desenvolvimento de células cancerígenas [2], e o elevado teor presente na goiaba $(54 \mu)$ é um fator que poderia contribuir para o aumento no interesse de exportação desta fruta.

Na goiaba, assim como na maioria das frutas, a textura está intimamente ligada à estrutura celular e à composição péctica [16], podendo variar conforme a intensidade do processo e grau de maturação da fruta. Instrumentalmente, a textura de produtos sólidos pode ser determinada através das propriedades mecânicas utilizando equipamentos que procuram mensurar ca- 
racterísticas sensoriais como dureza, firmeza e elasticidade.

O objetivo deste trabalho foi determinar as características físico-químicas, a cor e a textura (propriedades mecânicas) de 4 marcas de goiaba em calda industrializadas por métodos instrumentais, bem como verificar por meio da análise sensorial, as características de maior preferência pelo consumidor.

\section{2 - MATERIAL E MÉTODOS}

\section{1 - Material}

Goiabas em calda industrializadas de quatro marcas comerciais, consideradas como as mais representativas do mercado interno brasileiro, foram adquiridas no mercado local de Campinas/SP em janeiro de 2000. Foram adquiridas 3 latas de cada marca, todas dentro do prazo de validade. De cada lata, 2 metades de goiabas foram retiradas e drenadas para que fossem analisadas. A codificação utilizada para as amostras foi: 1, 2, 3 e 4 . Goiabas frescas da variedade Paluma foram adquiridas no CEASA/SP para fins comparativos, considerando que esta é a variedade mais utilizada no processamento da goiaba em calda [3].

\section{2 - Métodos}

\subsection{1 - Análises químicas e físico-químicas}

O teor de açúcares totais foi determinado pelo método titulométrico Lane-Eynon [13], e a umidade por método gravimétrico [1]. $\mathrm{O} \mathrm{pH}$ foi determinado em um pHmetro Analyser modelo 300, e o teor de sólidos totais foi determinado em refratômetro de bancada (Zeiss, Alemanha) através de leitura direta, a temperatura ambiente $\left(25^{\circ} \mathrm{C}\right)$.

A atividade de água das amostras foi medida em higrômetro Aqualab CX-2T (Decagon Devices Inc., USA) previamente calibrado com soluções saturadas de cloreto de sódio, cloreto de potássio e água deionizada. Foram consideradas as leituras com desvios de $\pm 0,003$. Todas as determinações foram feitas em triplicata.

\subsection{2 - Avaliação de cor instrumental}

A cor instrumental das frutas foi avaliada através de um espectrofotômetro de bancada Color Quest II (Hunter Lab, Reston, USA). O módulo de calibração utilizado foi reflectância especular excluída (RSEX), com padrões branco $(X=77,46 ; Y=82,08 ; Z=88,38)$ e cinza $(X=47,71 ; Y=50,83 ; Z=54,94)$, com uma fonte de iluminação D65 e ângulo visual de $10^{\circ}$. As coordenadas CIELab (a*, b*, L*) foram lidas diretamente do aparelho e a tonalidade $\left(\mathrm{H}^{*}\right)$ foi calculada de acordo com a Equação 1.

$$
H^{*}=\arctan \left(\frac{b^{*}}{a^{*}}\right)
$$

onde:L* é a luminosidade; a*, o parâmetro de croma vermelho-verde e $b^{*}$, o parâmetro de croma amarelo- azul. As leituras foram realizadas em amostras escolhidas aleatoriamente com 6 replicatas. A estimativa de desvio padrão entre as leituras foi de 0,05 a 1 .

A absorvância da calda a 540nm foi medida em espectrofôtometro Beckman Modelo DU-70, Série 52300 - USA.

\subsection{3 - Avaliação das propriedades mecânicas}

Ensaios de compressão uniaxial foram realizados em um texturômetro universal TA XT2i Texture Analyser (Stable Micro Systems, Surrey, UK) a $25^{\circ} \mathrm{C} \pm 1^{\circ} \mathrm{C}$. A compressão das amostras foi realizada com uma placa de acrílico lubrificada de $30 \mathrm{~mm}$ de diâmetro até $80 \%$ da sua altura inicial, com velocidade de compressão de $1 \mathrm{~mm} / \mathrm{s}$. A partir das curvas de força-altura obtidas foram calculados a tensão $(\sigma)$ (Equação 2), a deformação de Hencky $\left(\varepsilon_{\mathrm{H}}\right)$ (Equação 3), o módulo de elasticidade (E) e o trabalho na ruptura $\left(\mathrm{W}_{\text {rup }}\right)$. As características de ruptura da amostra foram descritas pela tensão $\left(\sigma_{\text {rup }}\right)$ e deformação $\left(\varepsilon_{\text {Hrup }}\right)$ na ruptura (Figura 1 ), as quais podem ser associadas à dureza e elasticidade, respectivamente. O módulo de elasticidade (E) e o trabalho na ruptura $\left(\mathrm{W}_{\text {rup }}\right)$ foram calculados através dos gráficos $\sigma$ (tensão) $-\varepsilon_{\mathrm{H}}$ (deformação) (Figura 1) sendo que $\mathrm{W}_{\text {rup }}$ é dado pela área sob a curva até o ponto de ruptura e o módulo de elasticidade, pelo coeficiente angular da parte linear inicial da curva [15].

$$
\begin{aligned}
\sigma & =\frac{F(t)}{A(t)} \\
\varepsilon_{H} & =\left|\ln \left(\frac{H(t)}{H_{0}}\right)\right|
\end{aligned}
$$

sendo $F(t)$ a força do material em um tempo $t(N), A(t)$ a área em função do tempo $\left(\mathrm{m}^{2}\right)$ considerando material incompressivel, $\mathrm{H}_{0}$ e $\mathrm{H}(\mathrm{t})$ a altura da amostra inicial e em um tempo $\mathrm{t}(\mathrm{m})$.

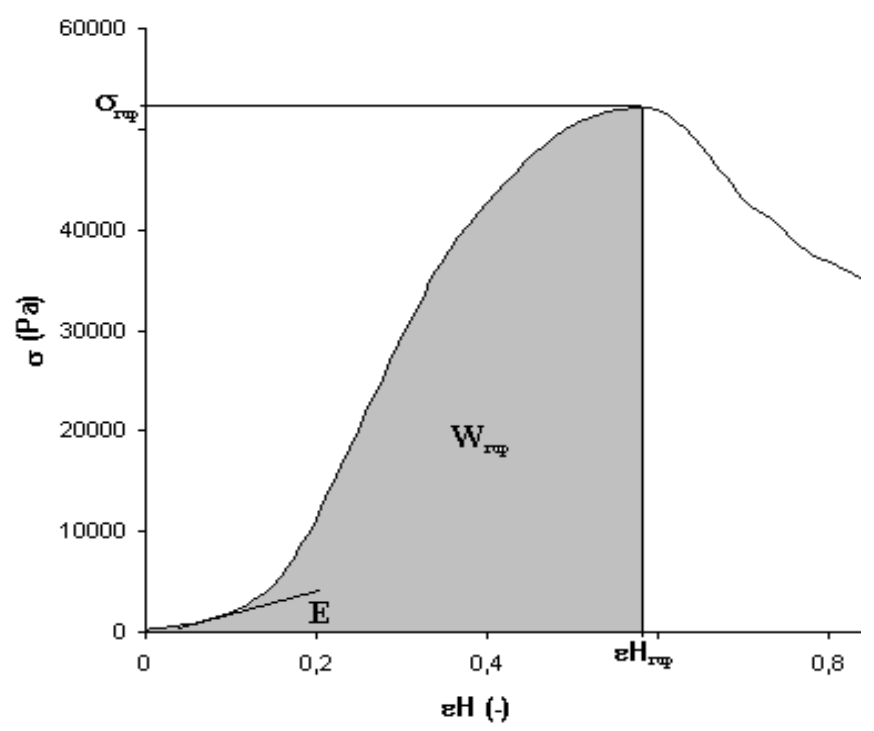

FIGURA 1. Propriedades mecânicas dadas pela curva $\sigma-\varepsilon_{\mathrm{H}}$ 
Um elevado número de repetições foi necessário na obtenção das propriedades mecânicas das goiabas em calda, pois se trata de sólidos cujas propriedades são determinadas pela estrutura celular e pela composição da parede; que são bastante influenciados pelas condições de processamento [12]. Portanto, pequenas alterações durante o processamento, bem como uma falta de seleção rigorosa da matéria-prima podem ser fatores que levaram ao elevado desvio nos resultados, apesar do cuidado rigoroso no preparo da amostra para a análise.

\subsection{4 - Avaliação sensorial de preferência}

Um teste de ordenação foi realizado com uma equipe de 39 provadores não treinados, recrutados entre alunos e funcionários da Faculdade de Engenharia de Alimentos da UNICAMP. A cada provador, foram fornecidas 4 amostras de goiabas em calda, distribuídas aleatoriamente e codificadas com números de 3 (três) dígitos. De acordo com a preferência, foi solicitado aos voluntários ordenar as amostras utilizando como atributos sabor, textura e aparência global, conforme a ficha apresentada na Figura 2 [9].

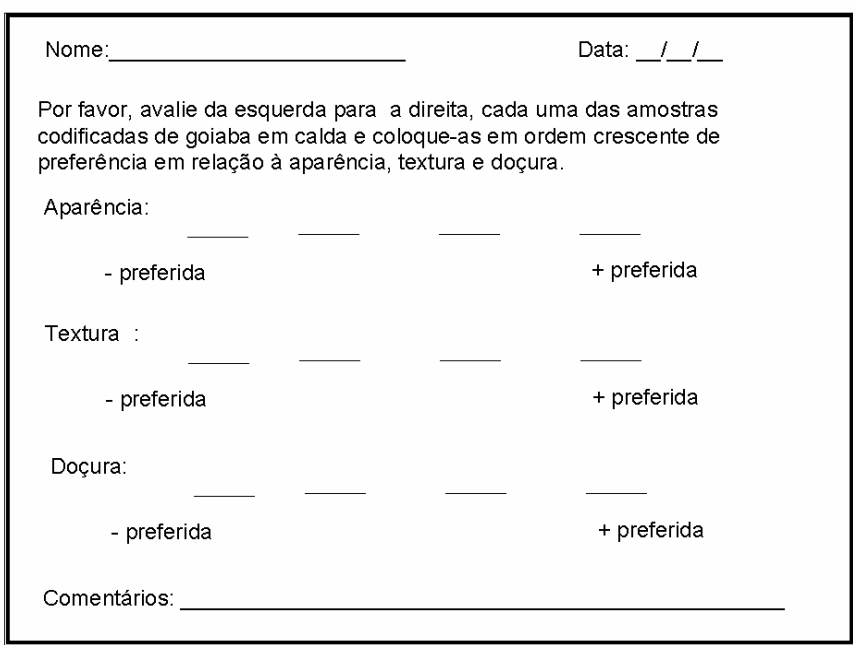

FIGURA 2. Modelo da ficha de aplicação do teste sensorial de preferência.

\subsection{5 - Análise estatística dos dados}

Os resultados dos ensaios de cor e propriedades mecânicas foram analisados estatisticamente pelo teste de Duncan, para avaliar se haviam diferenças significativas entre as amostras, considerando 95\% de confiança. Todas as amostras industrializadas e as in natura foram comparadas entre si.

$\mathrm{Na}$ análise sensorial foi utilizado um delineamento experimental de blocos completos casualizados que foram analisados pelo método de Friedman, com 95\% de confiança.

\section{3 - RESULTADOS E DISCUSSÃO}

\section{1 - Análises físico-químicas}

A Tabela 1 apresenta as características físico-químicas das goiabas em calda comerciais e fruta fresca.

TABELA 1. Características físico-químicas da goiaba in natura e das amostras industrializadas.

\begin{tabular}{c|cccc}
\hline \multirow{2}{*}{ Amostra } & \multicolumn{4}{|c}{ Fruta } \\
\cline { 2 - 5 } & UBU $(\%)^{\star}$ & AT $(\%)^{\star}$ & $\mathrm{Aw}^{\star}$ & $\mathrm{pH}$ \\
\hline In natura & $89,61 \pm 4,51 \times 10^{-3 \star \star}$ & $10,52 \pm 0,98^{\star *}$ & 0,991 & $3,6-4,0$ \\
1 & $65,89 \pm 1,43 \times 10^{-3 \star \star}$ & $31,36 \pm 0,90^{\star \star}$ & 0,958 & 3,93 \\
2 & $61,29 \pm 1,27 \times 10^{-3 \star *}$ & $25,60 \pm 0,93^{\star *}$ & 0,951 & 3,83 \\
3 & $67,52 \pm 2,54 \times 10^{-3 \star *}$ & $22,92 \pm 0,88^{\star *}$ & 0,967 & 3,79 \\
4 & $48,96 \pm 1,03 \times 10^{-3 \star *}$ & $40,19 \pm 1,03^{\star *}$ & 0,936 & 3,81 \\
\hline
\end{tabular}

* UBU: Umidade em base úmida, AT: Açúcares totais, Aw: Atividade de água. ** Estimativa de desvio padrão.

Os resultados mostram que o processo leva a uma diminuição da umidade e atividade de água (Aw), com o conseqüente aumento do teor de açúcares, devido ao efeito da pressão osmótica da calda de cobertura (Tabela 1). A amostra 4 diferiu das demais, pois apresentou um teor de açúcares muito maior que as demais amostras (de 30 a 80\% maior), bem como um menor teor de umidade (de 25 a 38\% menor). A análise potenciométrica mostrou que todas as amostras analisadas encontram-se no intervalo de $\mathrm{pH}$ determinado na fruta fresca.

O teor de sólidos solúveis totais analisados nas amostras e nas suas caldas (Figura 3) apresentou equilíbrio necessário para comercialização do produto [7]. Temperaturas elevadas associadas a tempos prolongados de processo são fatores que podem danificar a estrutura celular, comprometendo a sua permeabilidade, de forma que a parede perca sua seletividade. Assim, o equilíbrio entre a fruta e a calda pode ter sido alcançado mais facilmente.

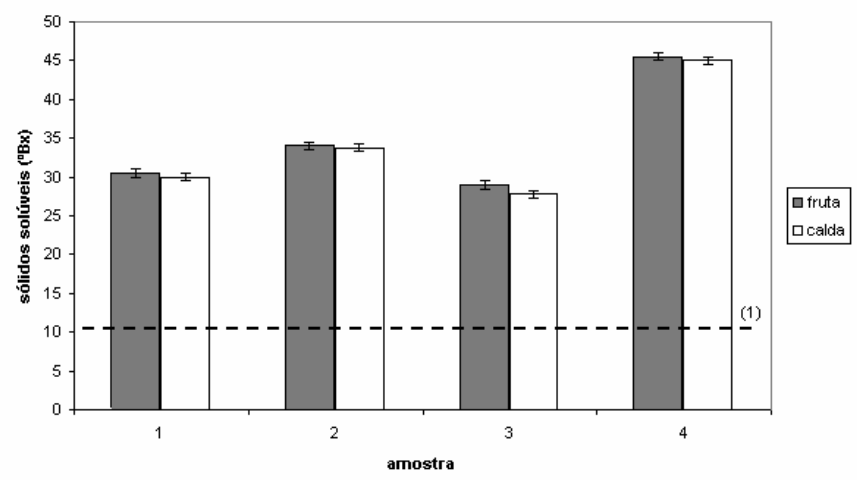

(1) A linha tracejada indica o teor de sólidos solúveis da fruta in natura

FIGURA 3. Teor de sólidos solúveis da fruta e da calda nas amostras de goiabas em calda. 


\section{2 - Cor}

A absorvância da calda (Tabela 2) pode ser relacionada com o teor de sólidos solúveis das diferentes marcas (Figura 3). Assim, o aumento da densidade óptica pode ser uma conseqüência do conteúdo de açúcares da calda, e das reações não enzimáticas favorecidas pelo tratamento térmico.

TABELA 2. Absorvância da calda das diferentes amostras de goiaba em calda.

\begin{tabular}{cc}
\hline Amostra & Absorvância da calda (540nm) \\
\hline 1 & 0,2773 \\
2 & 0,3031 \\
3 & 0,2226 \\
4 & 0,4643 \\
\hline
\end{tabular}

Na Tabela 3, encontram-se os valores de croma (a*, $\left.\mathrm{b}^{*}\right)$, luminosidade (L*) e tonalidade $\left(\mathrm{H}^{*}\right)$ obtidos para as amostras de goiaba em calda e para a fruta fresca. Uma análise global dos valores apresentados mostra que o processamento, especialmente o tratamento térmico, altera a coloração das amostras processadas com relação à fruta fresca.

Os valores obtidos para o parâmetro a* (relacionado com a cor característica da fruta) nas amostras industrializadas foram menores que os da fruta fresca, porém similares entre as diferentes marcas $(21,2$ a 23,5), com exceção da amostra 3 que apresentou um valor ainda menor $(18,1)$. Este último resultado poderia ser atribuído à degradação dos carotenóides pelo calor, tempo de processamento e exposição à luz, ou ainda ao menor grau de maturação desta amostra em relação às demais. A presença de açúcares, ácidos e aminoácidos, assim como as condições de processamento são fatores que influem na alteração de cor, fazendo com que frutas vermelhas comecem a desenvolver pigmentos marrons ou fiquem mais claras [6]. No entanto, a avaliação química da fruta (alta umidade e atividade de água) e da calda (baixa absorvância) conduzem a concluir que esta diferença deve ser atribuída ao menor grau de maturação da fruta utilizada como matéria-prima.

As amostras 1, 2 e 4, não apresentaram diferença significativa $(\mathrm{p}<0,05)$ no parâmetro da luminosidade (L*), mas estes foram significativamente diferentes com relação à fruta fresca apresentando valores mais altos. $\mathrm{O}$ aumento de $\mathrm{L}^{*}$, pode ser influenciado pela presença de açúcares na calda que aderidos à fruta conferem maior brilho, sendo detectado pelo equipamento como maior claridade.

A luminosidade da amostra 3 diferiu significativamente das outras amostras, corroborando o que havia sido observado no parâmetro $\mathrm{a}^{*}$, indicando a diferença no grau de maturação da fruta utilizada por esta marca com as demais.

$\mathrm{O}$ parâmetro $\mathrm{b}^{*}$ não mostrou variação significativa, uma vez que o amarelo não é a coloração predominante na parte interna da goiaba.
A tonalidade $\left(\mathrm{H}^{*}\right)$ da amostra tende a variar com o estágio de maturação em que ela se apresenta. Assim, quanto mais intensa a coloração característica (fruta mais madura), menor o valor de $\mathrm{H}^{*}$. Considerando que as frutas para a indústria de produtos em calda são normalmente maduras, a tonalidade das mesmas permaneceu similar nos diferentes lotes de cada amostra industrializada. As amostras 1 e 4 foram as que apresentaram tonalidade mais parecida a da fruta fresca.

TABELA 3. Luminosidade, parâmetros de croma e tonalidade de diferentes amostras de goiabas em calda

\begin{tabular}{ccccc}
\hline Amostra & $\mathrm{L}^{*}$ & $\mathrm{a}^{*}$ & $\mathrm{~b}^{\star}$ & $\mathrm{H}^{\star}$ \\
\hline In natura & $26,76^{\mathrm{c}}$ & $26,58^{\mathrm{c}}$ & $12,67^{\mathrm{c}}$ & 0,445 \\
1 & $36,64^{\mathrm{a}}$ & $23,43^{\mathrm{a}}$ & $10,79^{\mathrm{a}}$ & 0,432 \\
2 & $36,15^{\mathrm{a}}$ & $21,17^{\mathrm{b}}$ & $12,67^{\mathrm{b}}$ & 0,539 \\
3 & $41,86^{\mathrm{b}}$ & $18,08^{\mathrm{d}}$ & $11,60^{\mathrm{ab}}$ & 0,570 \\
4 & $37,08^{\mathrm{a}}$ & $23,52^{\mathrm{a}}$ & $12,19^{\mathrm{b}}$ & 0,478 \\
\hline
\end{tabular}

Médias na mesma coluna com letras iguais não apresentam diferença significativa $(\mathrm{p}<0,05)$

\section{3 - Propriedades mecânicas}

As propriedades mecânicas tensão e deformação na ruptura, bem como o módulo de elasticidade e o trabalho necessário para romper as amostras, são mostradas nas Figuras 4 a 7 .

A tensão necessária à ruptura das amostras das marcas 1 e 3 foi significativamente $(p<0,05)$ maior $(100-120 \mathrm{kPa})$ que a das marcas 2,4 e a fruta fresca $(40$ a $50 \mathrm{kPa}$ ). Fazendo a correlação desta propriedade com a textura da fruta, as amostras 1 e 3 apresentaram maior dureza. Isso pode ser atribuído à temperatura e/ou ao tempo de cozimento menor nestas amostras ( 1 e 3) ou menor grau de maturação, evitando assim o dano celular causado por estes parâmetros de processo. Nas amostras 2 e 4, a tensão obtida foi mais próxima a da fruta in natura, não apresentando diferença significativa entre elas $(\mathrm{p}>0,05)$.

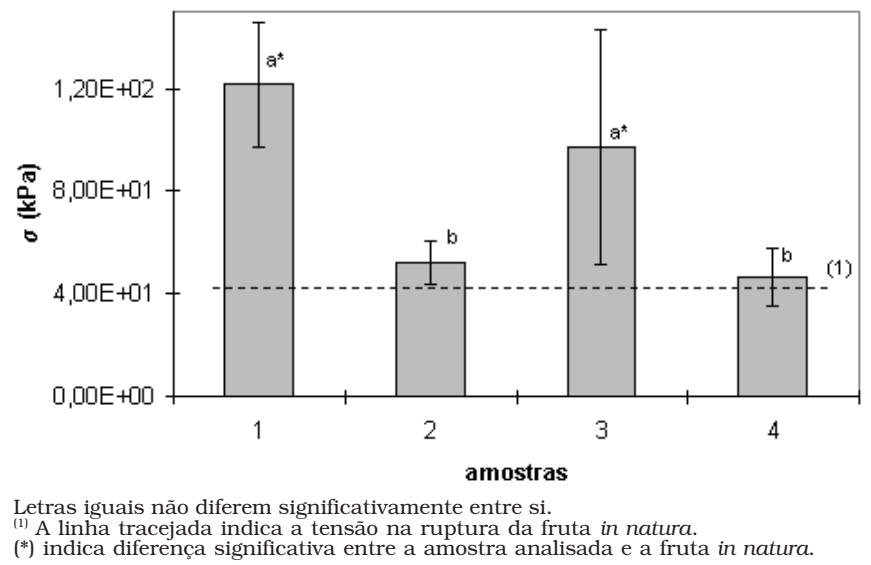

FIGURA 4. Tensão na ruptura das amostras de goiaba em calda e in natura.

Os valores obtidos de deformação na ruptura das 4 marcas avaliadas (Figura 5), apresentaram-se próximos 
entre si $(0,8-0,9)$ com diferença significativa para a amostra 4, cuja deformação foi maior $(1,0)$. Comparadas com a fruta fresca, houve um aumento geral na deformação das amostras, mostrando que o processamento tornou a fruta mais elástica.

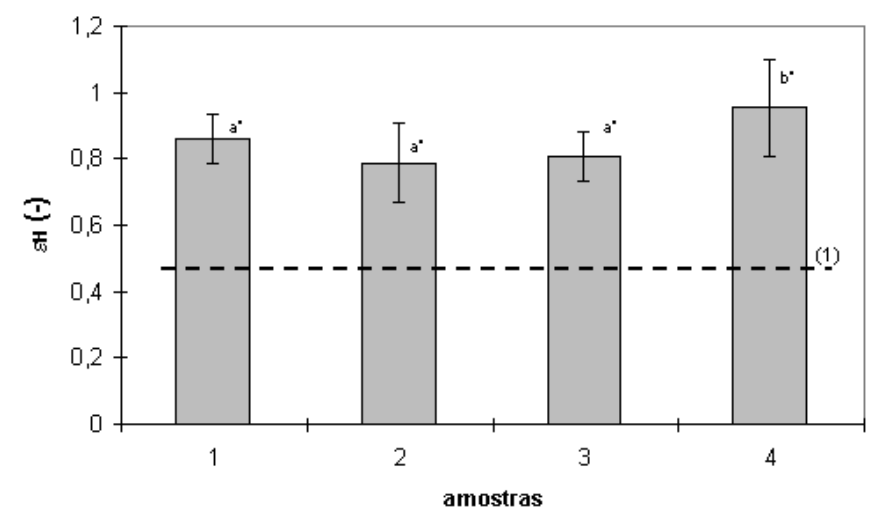

Letras diferentes mostram diferença significativa entre amostras.

(1) A linha tracejada indica a deformaçăo na ruptura da fruta in natura.

(*) indica diferença significativa entre a amostra analisada e a fruta in natura.

FIGURA 5. Deformação na ruptura das amostras de goiabas em calda e in natura.

A firmeza das goiabas em calda e da goiaba fresca foi determinada através do módulo de elasticidade que é uma propriedade intrínseca do material. Este parâmetro foi medido em um intervalo de deformação em que a amostra retorna à sua forma original, ou seja, não apresenta alterações irreversiveis da estrutura. Como a goiaba é um material celular, o módulo de elasticidade foi calculado em deformações muito pequenas, uma vez que altas deformações levariam à quebra da estrutura celular. Neste parâmetro, a análise estatística revela a similaridade entre as amostras 1-3 e 2-4 (Figura 6), seguindo a tendência dos resultados de tensão na ruptura. No entanto, a amostra 4 apresentou valores menores no módulo de elasticidade e na tensão durante a ruptura o que sugere um processamento mais drástico, que acabou por danificar permanentemente a estrutura celular. Com relação à fruta fresca, houve um aumento geral na firmeza das amostras de goiaba em calda.

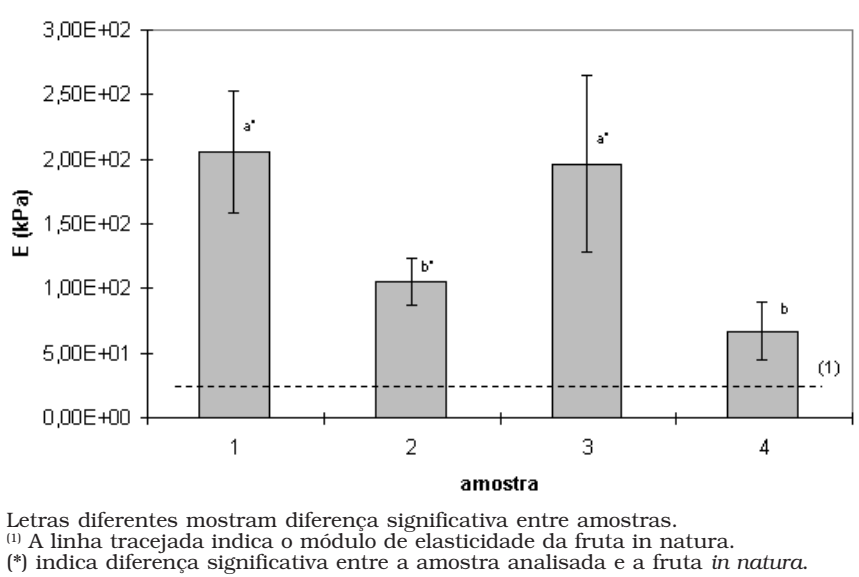

FIGURA 6. Módulo de elasticidade das amostras de goiaba em calda e in natura.
O trabalho na ruptura, que é o parâmetro que melhor se correlaciona com a energia necessária para a mordida, mostrou valores entre $10-60 \mathrm{~kJ} / \mathrm{m} 3$. No entanto, somente as amostras 1 e 2 apresentaram diferença significativa entre si, devido aos altos desvios padrão das amostras 3 e 4 .

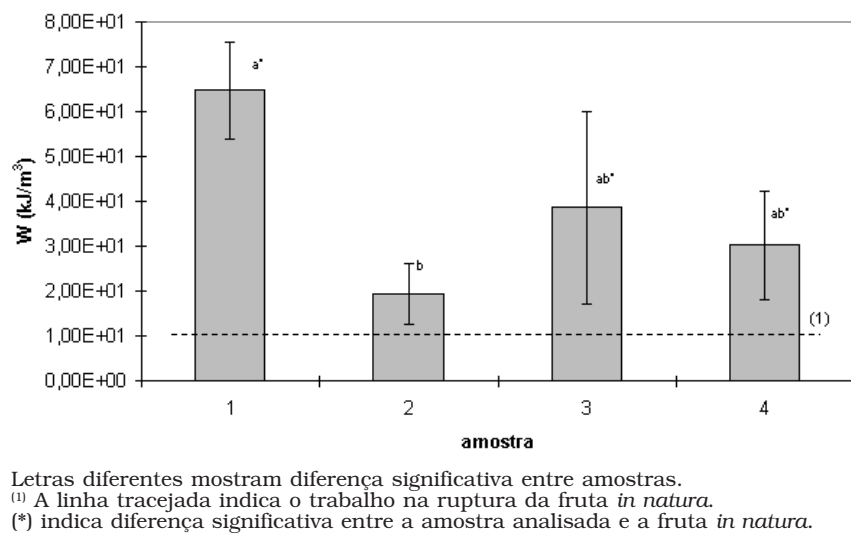

FIGURA 7. Trabalho na ruptura das amostras de goiaba em calda e in natura.

A análise das propriedades mecânicas mostrou alterações na estrutura da fruta quando processada. Alimentos tratados por processos térmicos geralmente apresentam produtos mais moles, principalmente devido à degradação da estrutura celular. No entanto, as análises físico-químicas mostram que outras condições, como o $\mathrm{pH}$ ácido e a quantidade de açúcares presente (Tabela 1), são condições que podem favorecer a gelificação da pectina naturalmente presente, com a formação de géis mais fortes [4, 14]. Assim, as condições de processo podem ter causado a gelificação da pectina presente na goiaba e/ou a entrada de açúcares na fruta fortalecendo a estrutura [8]. Neste caso, a fruta processada apresentou-se mais dura, firme e elástica que a fruta in natura.

\section{4 - Teste sensorial de ordenação e preferência}

Com a finalidade de conhecer a preferência dos consumidores com relação às marcas pesquisadas, foi realizado um teste sensorial de ordenação e preferência. Na Figura 8 encontram-se graficados os valores de ordenação de cada marca em cada um dos atributos avaliados. Os pontos mais afastados do centro do gráfico representam a amostra de menor preferência pelos consumidores.

Em relação à aparência, a amostra 4 foi a menos preferida pelos peovadores, diferindo significativamente $(\mathrm{p}<0,05)$ das outras amostras. Alguns provadores descreveram a amostra 4 como tendo muitos "fiapos", o que pode ter influenciado na avaliação.

No atributo doçura, só houve diferença significativa entre as amostras de menor preferência (amostra 3) e a de maior preferência (amostra 4). Os provadores associaram a preferência de doçura com a quantidade de açúcares presentes nas amostras (Tabela 1), sendo 
que a amostra 4, com maior teor de açúcares totais, foi a mais preferida.

A análise estatística das notas atribuídas pelos provadores para o atributo textura mostrou que a amostra 1 foi a preferida com relação às outras amostras. A avaliação geral do teste sensorial mostrou que a amostra 1 apresentou melhor aparência, textura e foi a mais preferida pelos provadores. É interessante observar que a amostra 1 foi a mais dura e firme juntamente com a 3 , que foi a menos preferida, mostrando que a textura da goiaba pode estar associada a outros fatores que não somente os obtidos pelas propriedades mecânicas.

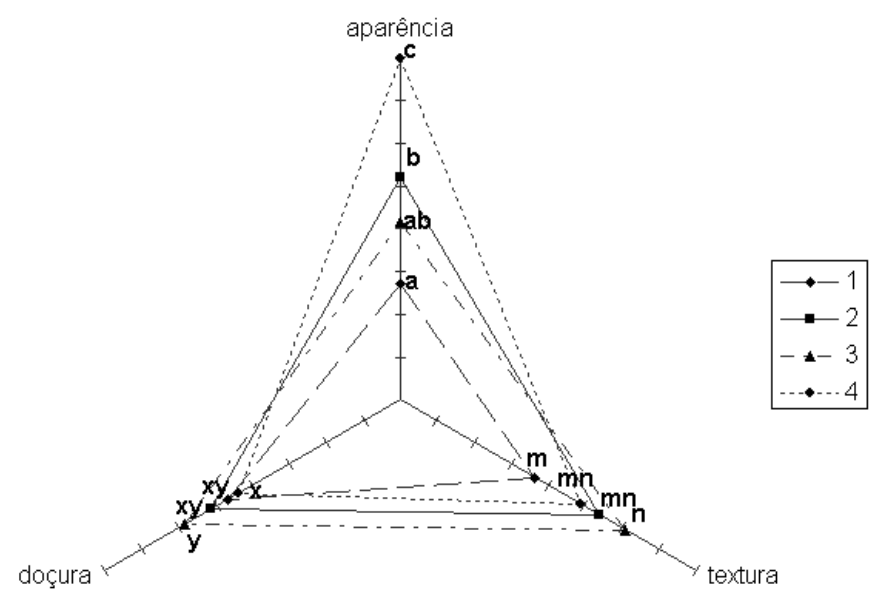

Letras diferentes mostram diferença significativa entre amostras.

FIGURA 8. Preferência de aparência, doçura e textura em diferentes amostras de goiaba em calda.

\section{4 - CONCLUSÕES}

O incremento de açúcares na fruta e as condições de processamento levaram à diminuição do parâmetro de cor a* (relacionado com a cor característica da fruta) nas amostras industrializadas em relação a fruta fresca. No entanto, estes foram similares entre as diferentes marcas $(21,2$ a 23,5$)$. A luminosidade ( $\left.L^{*}\right)$ aumentou com o processamento, provavelmente devido ao aumento de brilho proporcionado pela entrada de açúcares. As propriedades mecânicas que estão associadas com a textura da fruta mostraram um comportamento diferente do encontrado em outras frutas processadas. Em geral, as frutas processadas eram mais duras, elásticas e firmes que a fruta in natura, o que pode estar associado a alterações na estrutura celular da goiaba. A avaliação geral do teste sensorial mostrou que a amostra 1 (frutas mais duras e vermelhas) apresentou melhor aparência, textura e foi a mais preferida pelos provadores.

\section{5 - REFERÊNCIAS BIBLIOGRÁFICAS}

[1] A.O.A.C. Official Methods of Analysis. 13 ${ }^{\text {th }}$ ed. Washington: Association of Official Analytical Chemists, 1975.

[2] BRAMLEY, P.M. Is lycopene beneficial to human health? Phytochemistry, v. 54, n. 3, p. 233-236, 2000.

[3] CATI. Produção integrada de goiaba. Disponivel em: <http://www.cati.sp.gov.br/projetos/PIF/goiaba/ problemas_estrategicos_aserem_trabalhados.htm)> Acesso em: 08 de julho de 2003.

[4] CLARK, A.H.; FARRER, D.B. Shear modulus concentration relationships for low DE pectin - calcium gels in the temperature range $20-85^{\circ} \mathrm{C}$. Food Hydrocolloids, v. 10, n. 1, p. 31-39, 1996.

[5] FERREIRA, P.R. Goiaba deve atrair mais consumidores. Gazeta Mercantil, P. B-20, 25 DE ABRIL 2000.

[6] GOULD, W.A. Tomato Production, Processing and Technology. Baltimore: CTI Publisher, 1992.

[7] JACKIX, M.H. Doces, Geléias e Frutas em Calda (teórico e prático). Campinas: Editora da UNICAMP, 1988.

[8] KROKIDA, M.K.; KIRANOUDIS, C.T.; MAROULIS, Z.B. Viscoelastic behaviour of dehydrated products during rehydration. Journal of Food Engineering, v. 40, n. 4, p. 269-277, 1999.

[9] LAWLESS, H.T.; HEYMANN, H. Sensory Evaluation of Food: Principles and practices. Maryland: Aspen Publishers, 1999.

[10] MURAKAWA, F.E. São Paulo joga lixo 30 mil t de goiaba. Folha de São Paulo, Caderno Agrofolha, p. 5-6, 20 de janeiro 1998.

[11] PADULA, M.; RODRIGUEZ-AMAYA, D.B. Changes in individual carotenoids and vitamin $\mathrm{C}$ on processing and storage of guava juice. Acta Alimentaria, v. 16, p. 209-216, 1987.

[12] PELEG, M. Review: Mechanical properties of dry cellular solid foods. Food Science and Technology International, v. 3, n. 4, p. 227-240, 1997.

[13] RANGANNA, S. Manual Analysis of Fruit and Vegetable Products. New Delhi: Tata McGraw-Hill, 1978.

[14] SHARMA, S.K.; LIPTAY, A.; LE-MAGUER, M. Molecular characterization, physico-chemical and functional properties of tomato fruit pectin. Food Research International, v. 30, n. 7, p. 543-547, 1998.

[15] THYBO, A.K.; NIELSEN, M.; MARTENS, M. Influence of unaxial compression rate on rheological parameters and sensory texture prediction of cooked potatoes. Journal of Texture Studies, v. 31, n. 1, p. 25-40, 1999.

[16] TORREgGIANI, D.; BERTOLO, G. Osmotic pretreatments in fruit processing: chemical, physical and structural effects. Journal of Food Engineering, v. 49, n. 2-3, p. 247-253, 2001.

\section{6 - AGRADECIMENTOS}

Os autores agradecem à FAPESP e ao CNPq pelas bolsas concedidas. 